\title{
Métodos para superação da dormência de sementes de Parkinsonia aculeata L.
}

\section{Methods for overcoming dormancy of Parkinsonia aculeata L. seeds}

\author{
Pollyanna Freire Montenegro Agra ${ }^{1 *}$; Roberta Sales Guedes ${ }^{2}$; \\ Maria Lúcia Maurício da Silva ${ }^{3}$; Vênia Camelo de Souza \\ Leonaldo Alves de Andrade ${ }^{5}$; Edna Ursulino Alves ${ }^{5}$
}

\section{Resumo}

As sementes de Parkinsonia aculeata L. são dotadas de dormência tegumentar, o que lhes permite um longo período de sobrevivência no banco de sementes do solo, para que a germinação ocorra em condições favoráveis. Objetivou-se avaliar a influência de tratamentos pré-germinativos na superação da dormência de sementes de P. aculeata. As sementes foram submetidas aos seguintes tratamentos: testemunha - sementes intactas $\left(\mathrm{T}_{1}\right)$; escarificação mecânica com lixa d'água $\mathrm{n}^{\circ} 80$ na região lateral da semente $\left(\mathrm{T}_{2}\right)$; escarificação mecânica com lixa d'água $\mathrm{n}^{\circ} 80$, seguida de embebição em água à temperatura ambiente por 12 e 24 horas $\left(\mathrm{T}_{3}\right.$ e $\mathrm{T}_{4}$, respectivamente); imersão em ácido sulfúrico por 5, 10,15 e 20 minutos $\left(\mathrm{T}_{5}, \mathrm{~T}_{6}, \mathrm{~T}_{7}\right.$ e $\mathrm{T}_{8}$, respectivamente) e imersão em água na temperatura de $60,70,80$ e $90^{\circ} \mathrm{C}$ por 1 minuto $\left(\mathrm{T}_{9}, \mathrm{~T}_{10}, \mathrm{~T}_{11}\right.$ e $\mathrm{T}_{12}$, respectivamente). As características avaliadas foram: porcentagem de emergência, primeira contagem de emergência, índice de velocidade de emergência, comprimento e massa seca de plântulas. Para os tratamentos que envolveram a imersão em água na temperatura de 60, 70,80 e $90^{\circ} \mathrm{C}$ verificou-se baixos percentuais de emergência. A dormência tegumentar de sementes de P. aculeata é superada com máxima eficiência pela escarificação mecânica com lixa d' água, sugerindo que em ambiente natural, o movimento de contração e expansão dos solos resulta em uma escarificação mecânica no tegumento das sementes, permitindo, assim, alta taxa de germinação com distribuição ao longo do tempo.

Palavras-chave: Invasão biológica, germinação, tratamentos pré-germinativos

\begin{abstract}
The Parkinsonia aculeata L seeds have tegumentary dormancy, which makes them last for a long period in the seed bank of the earth so that their germination occurs in favorable conditions. Our aim was to evaluate the influence of pregermination treatments for overcoming the dormancy of $P$. aculeata seeds. The seeds were submitted to the following treatments: sample - intact seeds $\left(\mathrm{T}_{1}\right)$; mechanical scarification with water sandpaper no. 80, followed by room temperature water soaking for 12 and 24 hours $\left(\mathrm{T}_{3}\right.$ e $\mathrm{T}_{4}$, respectively); immersion in sulfuric acid for 5, 10, 15 and 20 minutes $\left(\mathrm{T}_{5}, \mathrm{~T}_{6}, \mathrm{~T}_{7}\right.$

${ }^{1}$ Eng $^{\mathrm{a}} \mathrm{Agr}^{\mathrm{a}}$, Prof ${ }^{\mathrm{a}} \mathrm{Dr}^{\mathrm{a}}$, Universidade Federal Rural do Semi-Árido, UFERSA, Campus Caraúbas, Caraúbas, RN. E-mail: pollyannaagra@ufersa.edu.br

${ }^{2}$ Bióloga, Prof $^{a} \operatorname{Dr}^{\mathrm{a}}$, Dept ${ }^{0}$ de Fitotecnia, Universidade Federal de Santa Catarina, UFSC, CCA, Florianópolis, SC. E-mail: guedes.r.s@ufsc.br

${ }^{3}$ Eng $^{\mathrm{a}} \mathrm{Agr}^{\mathrm{a}}$, Discente do Curso de Doutorado em Agronomia, Programa de Pós-Graduação em Agronomia, Universidade Federal da Paraíba, UFPB, CCA, Areia, PB. E-mail: luciagronomia@hotmail.com

${ }^{4}$ Bióloga, Prof $^{a} \operatorname{Dr}^{a}$, Dept ${ }^{\circ}$ de Ciências Básicas e Sociais, DCBS, CCHSA, UFPB, Bananeiras, PB. E-mail: vênia_camelo@

${ }^{5}$ Eng $^{\text {os }}$ Agr $^{\text {os }}$, Profs. Drs., Dept ${ }^{0}$ de Fitotecnia, UFPB, Centro de Ciências Agrárias, CCA, Areia, PB. E-mail: landrade@cca.ufpb. br; ednaursulino@cca.ufpb.br

* Autor para correspondência
\end{abstract} hotmail.com 
e $\mathrm{T}_{8}$, respectively); immersion in water in $60^{\circ} \mathrm{C}, 70^{\circ} \mathrm{C}, 80^{\circ} \mathrm{C}$ and $90^{\circ} \mathrm{C}$ for one minute $\left(\mathrm{T}_{9}, \mathrm{~T}_{10}, \mathrm{~T}_{11}\right.$ e $\mathrm{T}_{12}$, respectively). The characteristics evaluated were: percentage of emergence, emergence first count, emergence speed index, height and dry weight of seedlings. In the treatments that involved immersion in water in $60^{\circ} \mathrm{C}, 70^{\circ} \mathrm{C}, 80^{\circ} \mathrm{C}$ and $90^{\circ} \mathrm{C}$, a low percentage of emergence was obtained. The P. aculeate seeds tegumentary dormancy is overcome with maximum efficiency by the mechanical scarification with sandpaper, suggesting that, in natural environment the movement of contraction and expansion of the soil results in a mechanical scarification of the tegument of the seeds, thus, allowing a high percentage of germination with distribution as time passes.

Key words: Biological invasion, germination, pregermination treatments

\section{Introdução}

A espécie Parkinsonia aculeata L. (Fabaceae), arbórea, com altura variando de 5 a $8 \mathrm{~m}$, conhecida como turco ou espinho de Jerusalém, é nativa de regiões semiáridas da América Tropical. Foi introduzida em diversos países, principalmente com fins ornamentais, em função das características de suas flores, que são amarelas, perfumadas, dispostas em cachos axilares, pendentes, com cinco sépalas e número igual de pétalas livres e desiguais, sendo quatro amarelas com limbo mais ou menos arredondado e, a quinta mais alongada de um amarelo intenso, com a base nectarífera, manchas avermelhadas e cobertas de pelos (COCHARD; JACKES, 2005). Considerada uma espécie invasora, onde na Austrália infesta cursos de rios e açudes (WOODS, 1985); em Israel, foi descrita por Danin (2000) como uma agressiva colonizadora de terrenos baldios, aterros sanitários e marginais de rodovias; na África do Sul é invasora de ambientes ruderais e zonas ripárias (MASUBELELE; FOXCROFT; MILTON, 2009), provocando a exclusão da flora nativa (MAcDONALD et al., 2003) e, na Espanha também tem sido apontada como invasora (costa mediterrânea e Ilhas Canárias) dos mesmos ambientes descritos acima (SANZ-ELORZA; DANA-SÁNCHEZ; SOBRINO-VESPERINAS, 2004). No semiárido nordestino, nas últimas décadas tem se revelado como planta invasora. Forma densas populações em alguns habitats e, embora tenha preferência por ambientes alagados (KLINKEN, 2006), não raramente é encontrada em terras altas e até mesmo em ambientes secos, como se tem observado em vastas áreas da caatinga e ecossistemas associados.
As sementes de muitas espécies florestais permanecem viáveis por longos períodos no banco de sementes do solo, sendo a germinação lenta e irregular, mesmo quando expostas a condições ambientais favoráveis, como umidade, temperatura e luminosidade ideais (MURDOCH; ELLIS, 2000). Esse fenômeno é denominado dormência e consiste em estratégia natural de sobrevivência da semente no solo, após maturação e dispersão, para garantir a perpetuação da espécie (PIÑA-RODRIGUES; AGUIAR, 1993).

A dormência das sementes de leguminosas é uma característica hereditária, relativa à camada de células paliçádicas, as quais possuem paredes espessas e externamente recobertas por uma camada cuticular cerosa (POPINIGIS, 1985). Este fenômeno é causado por um bloqueio físico do tegumento resistente e impermeável que, ao impedir o trânsito aquoso e as trocas gasosas, não permite a embebição da semente nem a oxigenação do embrião, e que por isso permanece latente (GRUS; DEMATTË; GRAZIANO, 1984). Nas espécies invasoras esse fenômeno potencializa a capacidade de adaptação destas, uma vez que as sementes ficam latentes no banco de sementes do solo, podendo permanecer armazenadas por semanas, meses e até anos, até que condições ambientais favoráveis como luz, umidade e temperatura desencadeiem o processo de germinação.

As sementes dormentes alcançam grande longevidade, e qualquer procedimento que permita romper o tegumento, fazendo-as absorver água, promove sua germinação e emergência de plântulas geralmente vigorosas 
(GRUS; DEMATTË; GRAZIANO, 1984). A impermeabilidade do tegumento pode ser superada por meio da escarificação que causa uma ruptura ou o seu enfraquecimento, permitindo desta forma a absorção de água pela semente e o início do processo germinativo (MAYER; POLJAKOFFMAYBER, 1989). Vários são os métodos utilizados na superação da dormência, entre eles destacam-se a escarificação mecânica, química com ácido sulfúrico e a imersão em água quente (ALBUQUERQUE et al., 2007), sendo os dois primeiros métodos também indicados pelas Regras para Análise de Sementes (BRASIL, 2009).

A escarificação mecânica do tegumento foi eficiente na superação da dormência das sementes de várias espécies da família Fabaceae como, por exemplo, Cassia fistula L. (BEZERRA et al., 2014; GUEDES et al., 2013), Erythrina velutina Willd (SANTOS et al., 2013) e Centrosema plumieri Benth (GAMA et al., 2011).

A escarificação química com ácidos é muito eficiente, mas deve ser aplicada com certo cuidado, uma vez que longos períodos de exposição causam danos às sementes e, consequentemente, redução na germinação, como também pode provocar a morte do embrião (EGLEY, 1972). A escarificação com ácidos foi empregada com eficiência na superação da dormência de sementes de Centrosema plumieri Benth (GAMA et al., 2011), Sesbania virgata (Cav.) Pers. (SOUZA et al., 2010) e Bowdichia virgilioides Kunth. (ALBUQUERQUE et al., 2007). No entanto, esses resultados diferem dos obtidos por Oliveira, Davides e Carvalho (2003), que relatam que a aplicação de ácido sulfúrico por 30 minutos resultou na morte de 100 e $97 \%$ de dois lotes de sementes de Peltophorum dubium (Spreng) Taub.

Outro método que também tem sido eficiente na superação da dormência de sementes com impermeabilidade tegumentar é o uso da água quente (FOWLER; BIANCHETTI, 2000), no entanto, a eficiência de tal tratamento depende das espécies, temperatura da água e do tempo de imersão durante escarificação (SCHMIDT, 2000). A escarificação com água quente foi empregada com eficiência na superação da dormência de sementes em Acacia manguim Willd. (RODRIGUES et al., 2008) e $P$. aculeata L., onde a germinação nessa espécie foi aumentada pela imersão em água fervente $\left(100^{\circ} \mathrm{C}\right)$ durante 5 segundos (FOURNIER, 2004). Esses resultados diferem dos obtidos por Borges et al. (2004), que não obtiveram sucesso na germinação de sementes de Tachigalia multijuga (Benth.) submetidas a pré-tratamentos com água a $90^{\circ} \mathrm{C}$ por 60 segundos e 30 minutos.

Diante do exposto, objetivou-se avaliar a influência de tratamentos pré-germinativos na superação da dormência de sementes de $P$. aculeata.

\section{Material e Métodos}

A pesquisa foi conduzida no Laboratório de Ecologia Vegetal (LEV), do Centro de Ciências Agrárias, Universidade Federal da Paraíba, (CCAUFPB), em Areia - PB. Os frutos de Parkinsonia aculeata L. foram coletados no município de Juazeirinho - PB, no leito e entorno de um açude. A área possui 48.788 ha e coordenadas geográficas de $7^{\circ} 2$ ' 3,4 " S e $36^{\circ} 30^{\prime} 16,6^{\prime \prime} \mathrm{W}$, encontra-se nos domínios da Savana Estépica (caatinga), sendo um ambiente totalmente distoante da paisagem dominante. O clima segundo classificação de Thornthwaite: DA'da' (semiárido), com índice de aridez de 56,49\% e precipitação média anual de 498 $\mathrm{mm}$.

Após a coleta, os frutos foram levados ao LEV para beneficiamento manual das sementes e depois submetidas aos tratamentos descritos na Tabela 1. A escarificação mecânica manual foi efetuada friccionando-se a região oposta à micrópila do tegumento das sementes à superfície abrasiva da lixa d'água $\mathrm{n}^{\circ} .80$, até se observar pequena exposição dos cotilédones, sendo a embebição realizada em temperatura ambiente. As sementes imersas em ácido sulfúrico (96\%) foram constantemente revolvidas com um bastão de vidro, objetivando 
uniformizar a sua ação abrasiva. Decorridos os períodos pré-estabelecidos, as sementes foram lavadas em água corrente, por 10 minutos, para que os resíduos do ácido fossem retirados. As variáveis analisadas foram:

Tabela 1. Tratamentos pré-germinativos utilizados para superação da dormência de sementes de Parkinsonia aculeata $\mathrm{L}$.

\begin{tabular}{l|l}
\hline \multicolumn{2}{l}{ Descrição dos tratamentos pré-germinativos } \\
\hline$T_{1}$ & Testemunha - sementes intactas \\
\hline$T_{2}$ & Escarificação mecânica com lixa d'água $n^{\circ} 80$ na região oposta à micrópila \\
\hline$T_{3}$ & Imersão em ácido sulfúrico por 5 minutos \\
\hline$T_{4}$ & Imersão em ácido sulfúrico por 10 minutos \\
\hline$T_{5}$ & Imersão em ácido sulfúrico por 15 minutos \\
\hline$T_{6}$ & Imersão em ácido sulfúrico por 20 minutos \\
\hline$T_{7}$ & Escarificação mecânica com lixa d'água $n^{\circ} 80$, seguida de embebição em água por $12 \mathrm{~h}$ \\
\hline$T_{8}$ & Escarificação mecânica com lixa d'água $\mathrm{n}^{\circ} 80$, seguida de embebição em água por $24 \mathrm{~h}$ \\
\hline$T_{9}$ & Imersão em água na temperatura de $60^{\circ} \mathrm{C}$ por 1 minuto \\
\hline$T_{10}$ & Imersão em água na temperatura de $70^{\circ} \mathrm{C}$ por 1 minuto \\
\hline$T_{11}$ & Imersão em água na temperatura de $80^{\circ} \mathrm{C}$ por 1 minuto \\
\hline$T_{12}$ & Imersão em água na temperatura de $90^{\circ} \mathrm{C}$ por 1 minuto \\
\hline
\end{tabular}

Fonte: Elaboração dos autores.

Emergência de plântulas: Após a aplicação dos tratamentos pré-germinativos as sementes foram submetidas ao teste de emergência, o qual foi instalado em casa de crescimento, com quatro repetições de 25 sementes, distribuídas em bandejas plásticas com dimensões de $0,40 \times 0,40 \times 0,11 \mathrm{~m}$, contendo areia lavada e esterilizada, sendo realizadas regas diárias para manutenção da umidade do substrato (Figura 1). As contagens foram diárias, do terceiro aos 21 dias da instalação do teste quando verificouse estabilização da emergência, computando-se as plântulas que emitiram o epicótilo e, os resultados foram expressos em porcentagem.

Primeira contagem de emergência: conduzida conjuntamente com o teste de emergência, onde se computou as plântulas que haviam emergido no terceiro dia após a semeadura, sendo os resultados expressos em porcentagem.

\section{Índice de velocidade de emergência (IVE):} determinado mediante contagem diária do número de plântulas emersas durante 21 dias e o índice determinado de acordo com a fórmula proposta por Maguire (1962); onde

$$
I V E=\frac{E_{1}+E_{2}+\ldots+E_{n}}{N_{1}+N_{2}+\ldots+N_{n}}
$$

em que IVE = índice velocidade de emergência; $\mathrm{E}_{1}$, $\mathrm{E}_{2}, \ldots \mathrm{E}_{\mathrm{n}}=$ número de plântulas normais emergidas a cada dia; $\mathrm{N}_{1}, \mathrm{~N}_{2}, \ldots \mathrm{N}_{\mathrm{n}}$ = número de dias decorridos da semeadura da primeira até a última contagem.

Comprimento de plântulas: ao final do teste de emergência, as plântulas normais (que apresentaram radícula, epicótilo e hipocótilo) de cada repetição foram medidas da raiz até a parte aérea (inserção das plúmulas), com o auxílio de uma régua graduada em centímetros, sendo os resultados expressos em $\mathrm{cm} /$ plântula (Figura 1). 
Figura 1. Ilustrações da semeadura e emergência de plântulas de Parkinsonia aculeata L. oriundas de sementes submetidas a diferentes tratamentos pré-germinativos.
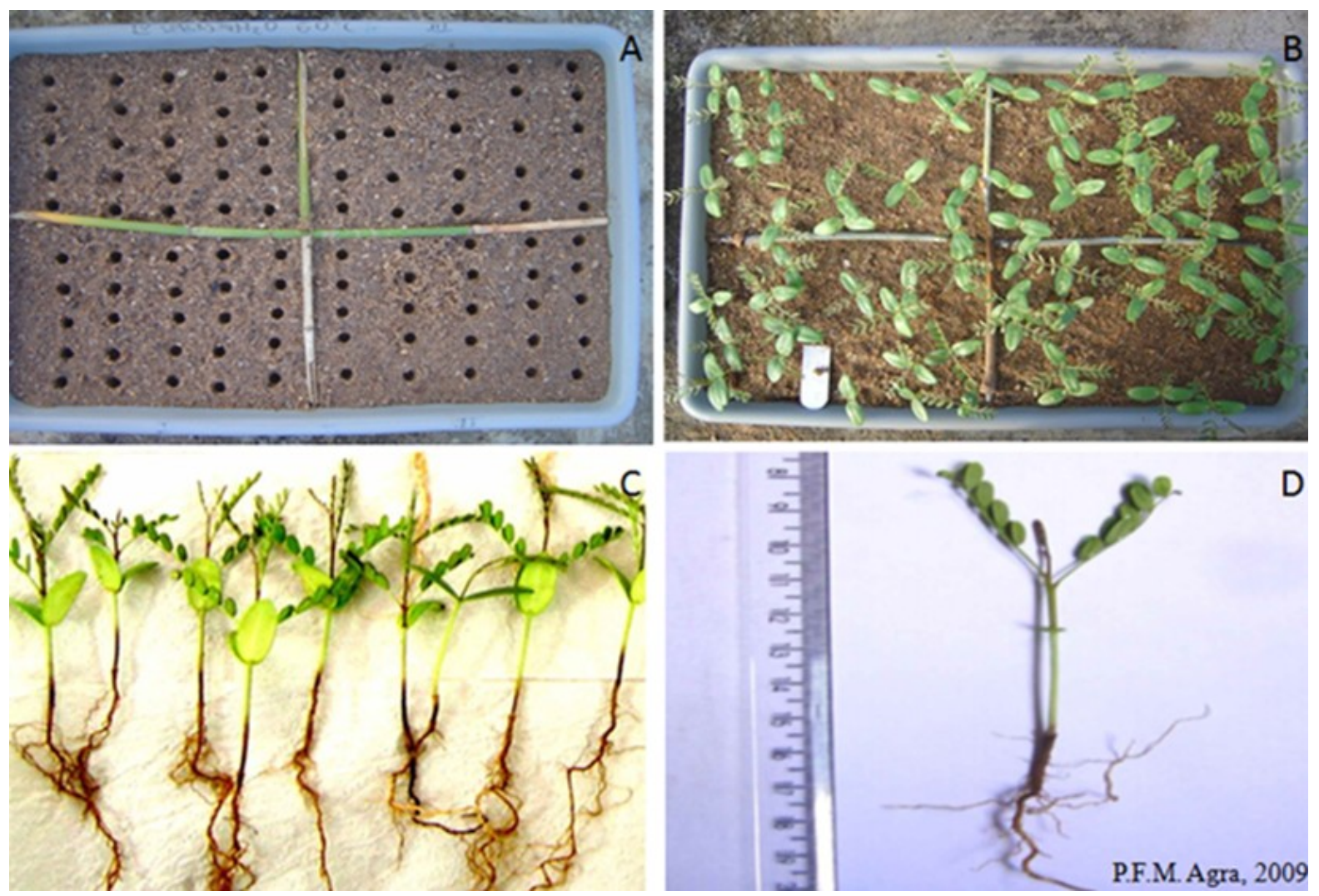

Fonte: Elaboração dos autores.

Massa seca de plântulas: após a medição do comprimento de plântulas, estas foram acondicionadas em sacos de papel "Kraft" sem os cotilédones e colocadas em estufa regulada a $65^{\circ} \mathrm{C}$ até atingir peso constante (48 horas) e, em seguida pesadas em balança analítica com precisão de 0,001 g, conforme metodologia de Nakagawa (1999).

O Delineamento experimental utilizado foi o inteiramente ao acaso com 4 repetições de 25 sementes por tratamento. Os dados obtidos, não transformados, foram submetidos à análise de variância pelo teste $\mathrm{F}$ e as médias comparadas pelo teste de Scott-Knott, a $5 \%$ de probabilidade.

\section{Resultados e Discussão}

Pelos dados médios relativos à emergência de plântulas de P. aculeata (Figura 2) constatou- se que as sementes submetidas ao tratamento $T_{2}$ (escarificação mecânica com lixa d'água $\mathrm{n}^{\circ} 80$ ) resultaram em maior percentual de emergência de plântulas (99\%), seguido das sementes imersas em ácido sulfúrico por 5 minutos $\left(\mathrm{T}_{3}\right)$. $\mathrm{O}$ aumento dos períodos de imersão em ácido sulfúrico (10, 15 e 20 minutos) foi danoso à emergência, possivelmente por ter penetrado na semente e afetado estruturas essências, em especial o eixo embrionário.

Esses resultados indicam que a dormência tegumentar foi superada satisfatoriamente quando as sementes foram submetidas à escarificação mecânica com lixa d'água. Segundo Hartmann et al. (1997) para espécies com sementes de tegumento impermeável à água, um dos tratamentos mais comumente usados é a escarificação mecânica. Como as sementes de $P$. aculeata são dispersas pela água e ficam armazenadas por longos períodos em 
solos alagados, provavelmente o movimento de contração e expansão dos solos, quando passam da estação alagada para a estação seca, pode causar uma escarificação mecânica no tegumento das sementes, favorecendo a embebição e a germinação da espécie.

Figura 2. Emergência de plântulas de Parkinsonia aculeata L. oriundas de sementes submetidas a diferentes tratamentos pré-germinativos.

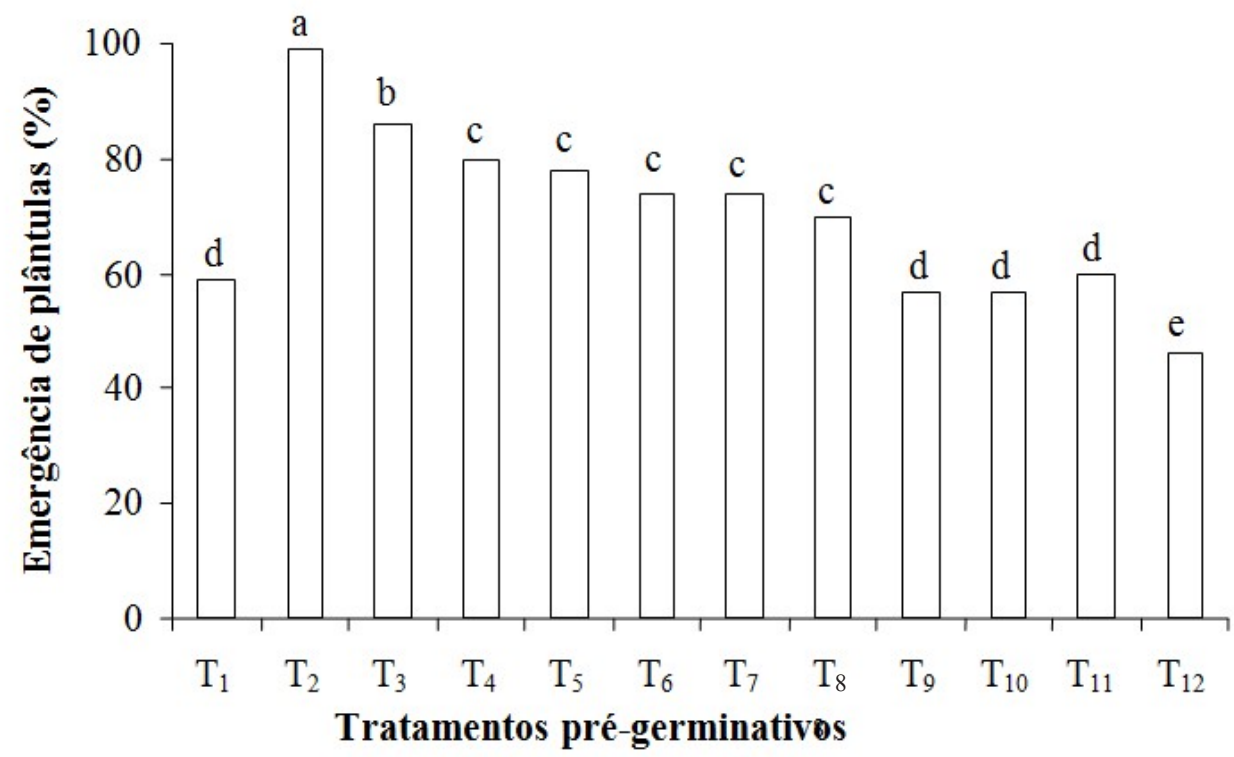

\begin{abstract}
Testemunha - sementes intactas $\left(\mathrm{T}_{1}\right)$; escarificação mecânica com lixa d'água $\mathrm{n}^{\circ} 80$ na região lateral da semente $\left(\mathrm{T}_{2}\right)$; escarificação mecânica com lixa d'água $\mathrm{n}^{\circ} 80$, seguida de embebição em água à temperatura ambiente por 12 e 24 horas ( $\mathrm{T}_{3}$ e $\mathrm{T}_{4}$, respectivamente); imersão em ácido sulfúrico por $5,10,15$ e 20 minutos $\left(\mathrm{T}_{5}, \mathrm{~T}_{6}, \mathrm{~T}_{7}\right.$ e $\mathrm{T}_{8}$, respectivamente) e imersão em água na temperatura de $60,70,80 \mathrm{e} 90^{\circ} \mathrm{C}$ por 1 minuto $\left(\mathrm{T}_{9}, \mathrm{~T}_{10}, \mathrm{~T}_{11}\right.$ e $\mathrm{T}_{12}$, respectivamente).

Fonte: Elaboração dos autores.
\end{abstract}

Embora a existência de tegumento impermeável seja uma característica indesejável do ponto de vista de manejo, fazendo com que as sementes tenham resistência à germinação, a mesma também é reconhecida por proteger a semente das flutuações de temperatura, umidade e da incidência de microrganismos o que explica, em parte, o elevado potencial invasor das sementes de $P$. aculeata de formar bancos de sementes no solo.

Os tratamentos $\mathrm{T}_{9}, \mathrm{~T}_{10}, \mathrm{~T}_{11}$ e $\mathrm{T}_{12}$ (imersão em água a temperatura de $60,70,80$ e $90^{\circ} \mathrm{C}$ por um minuto) resultaram em menores percentuais de emergência de plântulas. A redução na porcentagem de emergência oriundas destes tratamentos pode estar relacionada ao fato de que apenas a imersão das sementes nas temperaturas citadas pode não ter sido suficiente para superar a dormência, uma vez que Trujillo (1995) constatou que a germinação de sementes de $P$. aculeata é aumentada quando estas são imersas em água fervente a $100^{\circ} \mathrm{C}$ durante 5 segundos e, depois colocadas para embeber por 24 horas.

Para o tratamento $T_{1}$ (sementes intactas), observou-se percentagem de emergência de plântulas em torno de $60 \%$, indicando que nem todas as sementes dispersas pela espécie têm impermeabilidade do tegumento à água, ou seja, ocorre uma variação no número de sementes dormentes dentro da mesma população. Essa variação na impermeabilidade do tegumento das sementes pode ser de caráter genético ou ambiental, conforme observado por Andersson e Milberg (1998) 
com outras espécies. Veasey, Freitas e Schammass (2000), estudando a maturação de sementes do gênero Sesbania verificaram grande variação na intensidade de dormência entre e dentro das espécies, sendo um fator importante na dinâmica de populações naturais, e está relacionada à adaptação dos indivíduos a ambientes heterogêneos.

Um fator a ser considerado é que, o elevado número de sementes germinadas sem tratamentos pré-germinativos, origina o banco de plântulas da espécie e as demais que não germinaram, imediatamente, são responsáveis pela formação do banco de sementes. Essas características podem justificar o elevado potencial invasor da espécie no semiárido paraibano.

Quanto ao índice de velocidade de emergência (Figura 3) verificou-se que o tratamento $T_{2}$ (escarificação mecânica com lixa d'água $n^{\circ} 80$ ) foi responsável pelos maiores valores de IVE, seguido do tratamento $\mathrm{T}_{8}$ (escarificação mecânica com lixa d'água $\mathrm{n}^{\circ} 80$, seguida de embebição em água à temperatura ambiente por 24 horas), indicando que este método promoveu o rompimento da camada impermeável das sementes, permitindo a entrada de água em quantidade adequada ao embrião, e consequentemente, aumentando a velocidade do processo germinativo. Nos tratamentos térmicos $\mathrm{T}_{9}, \mathrm{~T}_{10}, \mathrm{~T}_{11}$ e $\mathrm{T}_{12}$ constatou-se os menores índices de velocidade de emergência, indicando que estes tratamentos tornaram-se danosos ao vigor das sementes, enquanto os tratamentos com ácido sulfúrico $\left(\mathrm{T}_{3}, \mathrm{~T}_{4}, \mathrm{~T}_{5}\right.$ e $\left.\mathrm{T}_{6}\right)$ não diferiram estatisticamente entre si e também de $\mathrm{T}_{7}$ (escarificação mecânica seguida de embebição por 12h).

Figura 3. Índice de velocidade de emergência de plântulas de Parkinsonia aculeata L. oriundas de sementes submetidas a diferentes tratamentos pré-germinativos.

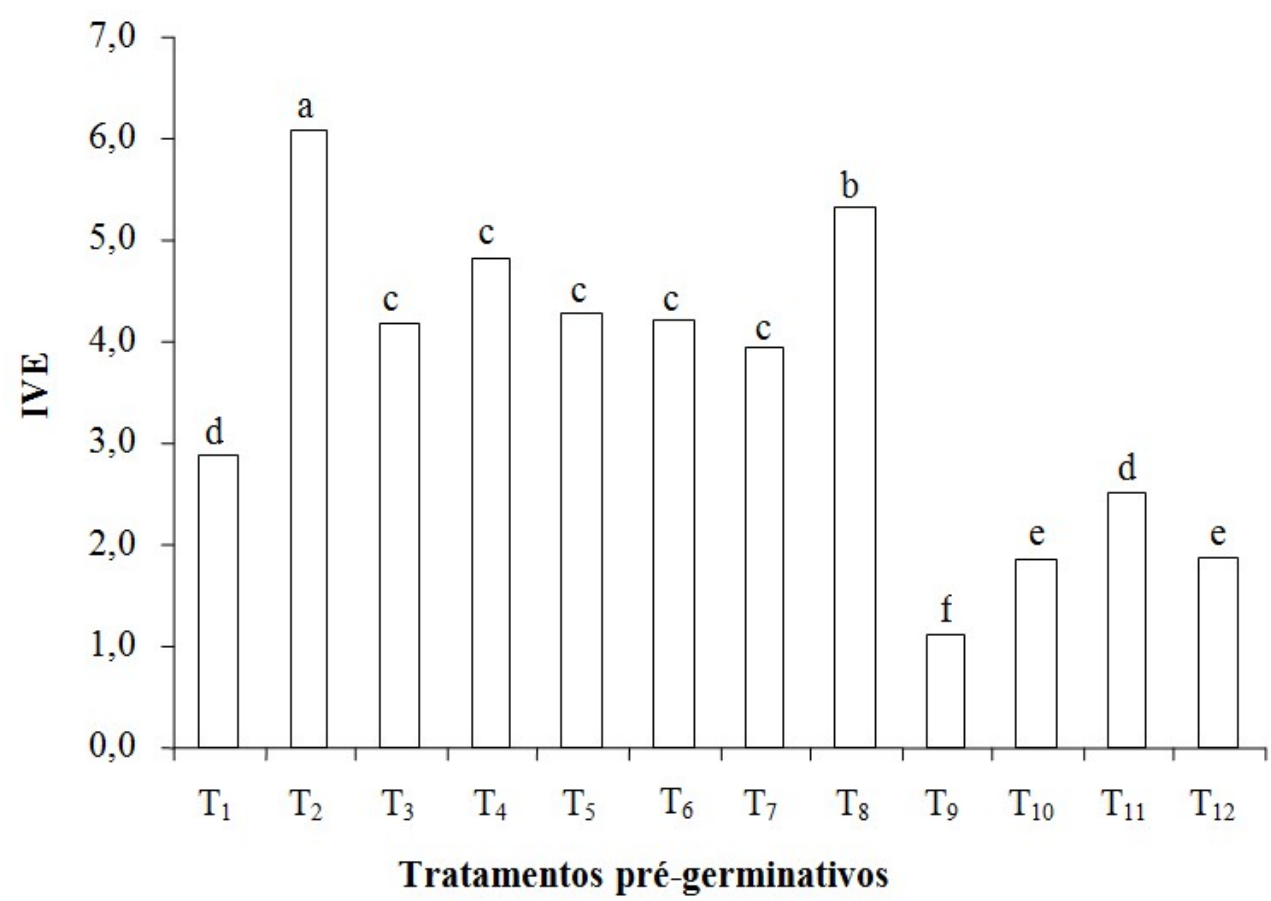

Testemunha - sementes intactas $\left(\mathrm{T}_{1}\right)$; escarificação mecânica com lixa d'água $\mathrm{n}^{\circ} 80$ na região lateral da semente $\left(\mathrm{T}_{2}\right)$; escarificação mecânica com lixa d'água $\mathrm{n}^{\circ} 80$, seguida de embebição em água à temperatura ambiente por 12 e 24 horas $\left(\mathrm{T}_{3}\right.$ e $\mathrm{T}_{4}$, respectivamente); imersão em ácido sulfúrico por 5, 10, 15 e 20 minutos $\left(\mathrm{T}_{5}, \mathrm{~T}_{6}, \mathrm{~T}_{7}\right.$ e $\mathrm{T}_{8}$, respectivamente) e imersão em água na temperatura de $60,70,80$ e $90^{\circ} \mathrm{C}$ por 1 minuto $\left(\mathrm{T}_{9}\right.$, $\mathrm{T}_{10}, \mathrm{~T}_{11}$ e $\mathrm{T}_{12}$, respectivamente).

Fonte: Elaboração dos autores. 
Em ambiente natural, a impermeabilidade do tegumento é superada por processos de escarificação, a qual consiste em qualquer tratamento que resulte na ruptura ou enfraquecimento do tegumento, permitindo a entrada de água e gases e, assim, dando início ao processo germinativo (MAYER; POLJAKOFF-MAYBER, 1989). Comprova-se pelos dados que as sementes da espécie $P$. aculeata são dormentes e para que a mesma esteja invadindo de forma desordenada as regiões mais áridas da Caatinga, acredita-se que o movimento de contração e expansão dos solos, pode causar uma escarificação mecânica no tegumento das sementes, permitindo, assim, a entrada de água para o interior da semente. Esse processo pode ocorrer, também, pela ação de ácidos durante a ingestão das sementes por animais dispersores, além da ação dos microrganismos do solo (VAZQUEZ-YANES; OROZCO-SEGOVIA, 1993).

A escarificação com lixa proporcionou os maiores índices de velocidade de emergência de plântulas de Merremia aegyptia L. (PEREIRA et al., 2007), no entanto, a imersão em ácido sulfúrico concentrado por nove minutos foi eficaz em aumentar a velocidade de germinação em sementes de Strelitzia reginae Ait. (BARBOSA et al., 2005), e por oito e dez minutos, em sementes de Caesalpinia pyramidalis Tul. (ALVES et al., 2007) e de Sesbania virgata (Cav.) Pers (SOUZA et al., 2010).

Os dados referentes ao vigor, determinado pela primeira contagem de emergência de plântulas de $P$. aculeata aos três dias estão apresentados na Figura 4. À semelhança da percentagem de emergência, os maiores porcentuais de plântulas normais (80\%) na primeira contagem também foram obtidos de sementes oriundas do tratamento $\mathrm{T}_{2}$ (escarificação mecânica com lixa d'água $n^{\circ} 80$ ). Nos tratamentos de escarificação mecânica com lixa d'água $n^{\circ} 80$, seguidos da embebição em água por 12 e $24 \mathrm{~h}\left(\mathrm{~T}_{7}\right.$ e $\mathrm{T}_{8}$, respectivamente), constatou-se redução do vigor com o aumento dos períodos de embebição, quando comparados ao tratamento apenas com escarificação, possivelmente, isto deve ter ocorrido pela brusca embebição.

A eficiência da escarificação mecânica foi constatada em provocar fissuras no tegumento das sementes, eliminando a impermeabilidade do tegumento destas. No entanto, Medeiros Filho, França e Innecco (2002) relataram que a escarificação mecânica pode ocasionar injúrias nas sementes pela fricção ou diferença de constituição de seus tegumentos em função da espécie. Os demais tratamentos (imersão em ácido sulfúrico, água quente na temperatura de $60,70,80$ e $90^{\circ} \mathrm{C}$, bem como a imersão em água por 12 e $24 \mathrm{~h}$ ) não foram eficientes, pois não permitiram que as sementes expressassem sua máxima qualidade fisiológica. Resultados semelhantes foram obtidos em sementes de Caesalpinia pyramidalis Tul. (ALVES et al., 2007). Para as sementes que não sofreram nenhum tratamento $\left(\mathrm{T}_{1}\right)$, observou-se que em apenas três dias emergiram $40 \%$ das plântulas. Esta variabilidade da dormência nas sementes dentro da espécie, do ponto de vista ecológico, indica provavelmente diferentes graus de adaptação da espécie a diferentes habitats.

Os dados relativos ao vigor baseado no comprimento das plântulas de $P$. aculeata são apresentados na Figura 5, pelos quais observou-se que o comprimento máximo de plântulas $(16,04 \mathrm{~cm})$ foi oriundo de sementes submetidas ao tratamento $\mathrm{T}_{2}$ (escarificação mecânica com lixa d'água $\mathrm{n}^{\circ} 80$, na região oposta a micrópila), seguido do tratamento $\mathrm{T}_{8}$ (escarificação mecânica com lixa d'água $\mathrm{n}^{\circ} 80$, seguida de embebição por $24 \mathrm{~h}$ ). 
Figura 4. Primeira contagem de emergência de plântulas de Parkinsonia aculeata L. oriundas de sementes submetidas a diferentes tratamentos pré-germinativos.

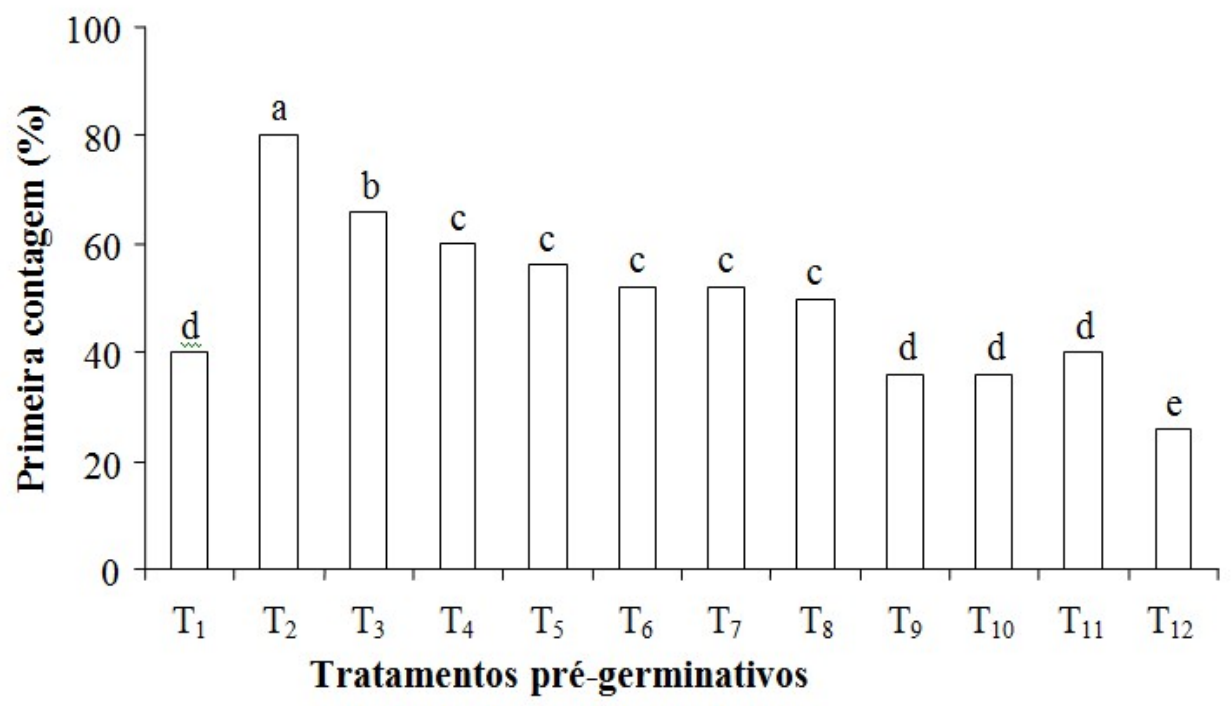

Testemunha - sementes intactas $\left(\mathrm{T}_{1}\right)$; escarificação mecânica com lixa d'água nº 80 na região lateral da semente $\left(\mathrm{T}_{2}\right)$; escarificação mecânica com lixa d'água $n^{\circ} 80$, seguida de embebição em água à temperatura ambiente por 12 e 24 horas $\left(\mathrm{T}_{3}\right.$ e $\mathrm{T}_{4}$, respectivamente); imersão em ácido sulfúrico por 5 , 10,15 e 20 minutos $\left(\mathrm{T}_{5}, \mathrm{~T}_{6}, \mathrm{~T}_{7}\right.$ e $\mathrm{T}_{8}$, respectivamente) e imersão em água na temperatura de $60,70,80$ e $90^{\circ} \mathrm{C}$ por 1 minuto $\left(\mathrm{T}_{9}, \mathrm{~T}_{10}, \mathrm{~T}_{11}\right.$ e $\mathrm{T}_{12}$, respectivamente).

Fonte: Elaboração dos autores.

Figura 5. Comprimento de plântulas de Parkinsonia aculeata L. oriundas de sementes submetidas a diferentes tratamentos pré-germinativos.

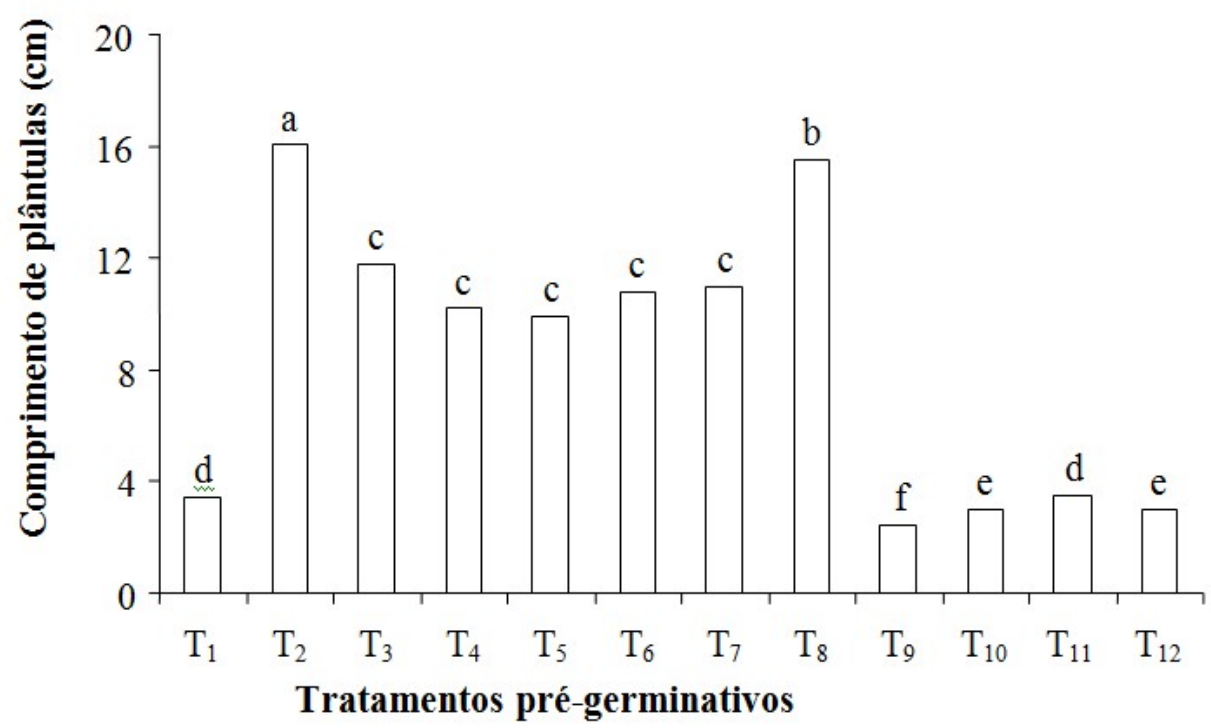

Testemunha - sementes intactas ( $\left.T_{1}\right)$; escarificação mecânica com lixa d'água $n^{\circ} 80$ na região lateral da semente $\left(\mathrm{T}_{2}\right)$; escarificação mecânica com lixa d'água $\mathrm{n}^{\circ} 80$, seguida de embebição em água à temperatura ambiente por 12 e 24 horas $\left(\mathrm{T}_{3}\right.$ e $\mathrm{T}_{4}$, respectivamente); imersão em ácido sulfúrico por $5,10,15$ e 20 minutos ( $\mathrm{T}_{5}, \mathrm{~T}_{6}, \mathrm{~T}_{7}$ e $\mathrm{T}_{8}$, respectivamente) e imersão em água na temperatura de 60 , 70,80 e $90^{\circ} \mathrm{C}$ por 1 minuto $\left(\mathrm{T}_{9}, \mathrm{~T}_{10}, \mathrm{~T}_{11}\right.$ e $\mathrm{T}_{12}$, respectivamente).

Fonte: Elaboração dos autores. 
Para as sementes imersas em ácido sulfúrico, independente do período de exposição, ocorreu redução no comprimento de plântulas, possivelmente isto deve ter ocorrido devido à ruptura do tegumento que permitiu a infiltração do ácido, atingido células essências, e desta forma comprometendo o desenvolvimento das plântulas, embora houvesse um alto porcentual de emergência, como foi registrado no tratamento $\mathrm{T}_{3}$ (imersão em ácido por 5 minutos); os dados referentes à massa seca de plântulas não diferiram estatisticamente entre si.

A maior longevidade das sementes em função da dormência e a formação de bancos de sementes no solo são fatores que constituem vantagem competitiva desta invasora sobre a biodiversidade autóctone, a qual deve ser potencializada significativamente com outras estratégias, a exemplo do rápido crescimento na fase de plântulas.

\section{Conclusões}

A dormência tegumentar de sementes de $P$. aculeata é superada com máxima eficiência pela escarificação mecânica com lixa d' água, sugerindo que em ambiente natural, o movimento de contração e expansão dos solos resulta em uma escarificação mecânica no tegumento das sementes, permitindo, assim, alta taxa de germinação com distribuição ao longo do tempo.

\section{Referências}

ALBUQUerque, K. S.; GUIMARÃES, R. M.; ALMEIDA, I. F.; CLEMENTE, A. C. S. Métodos para a superação da dormência em sementes de sucupirapreta (Bowdichia virgilioides Kunth.). Ciência e Agrotecnologia, Lavras, v. 31, n. 6, p. 1716-1721, 2007.

ALVES, E. U.; CARDoso, E. A.; BRUNO, R. L. A.; ALVES, A. U.; ALVES, A. U.; GALINDO, E. A.; BRAGA JÚNIOR, J. M. Superação da dormência de sementes de Caesalpinia pyramidalis Tul. Revista Árvore, Viçosa, MG, v. 31, n. 3, p. 405-415, 2007.
ANDERSSON, L.; MILBERG, P. Variation in seed dormancy among mother plants, populations and years of seed collection. Seed Science Research, Wallingford, v. 8, n. 1, p. 29-38, 1998.

BARBOSA, J. G.; ALVARENGA, E. M.; DIAS, D. C. F. S.; VIEIRA, A. N. Efeito da escarificação ácida e de diferentes temperaturas na qualidade fisiológica de sementes de Strelitzia reginae. Revista Brasileira de Sementes, Pelotas, v. 27, n. 1, p. 71-77, 2005.

BEZERRA, F. T. C.; ANDRADE, L. A.; BEZERRA, M. A. F.; SILVA, M. L. M.; NUNES, R. C. R.; COSTA, E. G. Biometria de frutos e sementes e tratamentos pré-germinativos em Cassia fistula L. (FabaceaeCaesalpinioideae). Semina: Ciências Agrárias, Londrina, v. 35, n. 4, p. 2273-2286, 2014. Suplemento 1.

BORGES, E. E. L.; RIBEIRO JUNIOR, J. I.; REZENDE, S. T.; PEREZ, S. C. J. G. A. Alterações fisiológicas em sementes de Tachigalia multijuga (Benth.) (mamoneira) relacionadas aos métodos para a superação da dormência. Revista Árvore, Viçosa, MG, v. 28, n. 3, p. 317-325, 2004.

BRASIL. Ministério da Agricultura, Pecuária e Abastecimento. Regras para análise de sementes. Secretaria de Defesa Agropecuária. Brasília: MAPA/ ACS, 2009.395p.

COCHARD, R.; JACKES, B. R. Seed ecology of the invasive tropical tree Parkinsonia aculeata. Plant Ecology, Roterdam, v. 180, n. 1, p. 13-31, 2005.

DANIN, A. The inclusion of adventive plants in the second edition of Flora Palaestina. Willdenowia, Beih, v. 30, n. 2, p. 305-314, 2000.

EGLEY, G. H. Influence of the seed envelope and growth regulators upon seed dormancy in witchweed (Stringa lutea Lour). Annals of Botany, London, v. 36, n. 147, p. 755-770, 1972.

FOURNIER, L. A. Parkinsonia aculeate L. Tropical Tree Seed, Manual-Part 2 Species Descriptions, 2004. p. 597598. Available at: <http://www.rngr.net/publications/ ttsm/species/PDF.2004-03-15.5909>. Accessed at: 21 may 2012.

FOWLER, A. J. P.; BIANCHETTI, A. Dormência em sementes florestais. Colombo: EMBRAPA Florestas, 2000. 27 p. (EMBRAPA Florestas. Documentos, 40).

GAMA, J. S. N.; ALVES, E. U.; BRUNO, R. L. A.; PEREIRA JUNIOR, L. R.; BRAGA JUNIOR, J. B. M.; MONTE, D. M. O. Superação de dormência em sementes de Centrosema plumieri Benth. Revista Brasileira de Sementes, Londrina, v. 33, n. 4, p. 645-653, 2011. 
GRUS, V. M.; DEMATTË, M. E. S. P.; GRAZIANO, T. T. Germinação de sementes de pau-ferro e cássia-javanesa submetidas a tratamentos para quebra de dormência. Revista Brasileira de Sementes, Brasília, v. 6, n. 2, p. 2936, 1984.

GUEDES, R. S.; ALVES, E. U.; SANTOS-MOURA, S. S.; COSTA, E. G.; MELO, P. A. F. R. Tratamentos para superar dormência de sementes de Cassia fistula L. Revista Biotemas, Florianópolis, v. 26, n. 4, p. 11-22, 2013.

HARTMANN, H. T.; KESTER, D.; DAVIES, F.; GENEVE, R. Plant propagation: principles and practices. $6^{\text {th }}$ ed. New Jersey: Simom \& Schuster, 1997. 770 p.

KLINKEN, R. D. Biological control of Parkinsonia aculeata: what are we trying to achieve? Australian Journal of Entomology, Malden, v. 45, n. 4, p. 268-271, 2006.

MACDONALD, I. A. W.; REASER, J. K.; BRIGHT, C.; NEVILLE, L. E.; HOWARD, G. W.; MURPHY, S. J.; PRESTON, G. Invasive alien species in southern Africa: national reports e directory of resources. Cape Town: Global Invasive Species Programme, 2003. 125 p.

MAGUIRE, J. D. Speed of germination aid in selection and evaluation for seeding emergence and vigor. Crop Science, Madison, v. 2, n. 2, p. 76-177, 1962.

MASUBELELE, M. L.; FOXCROFT, L. C.; MILTON, S. J. Alien plant species list and distribution for Camdeboo National Park, Eastern Cape Province. South África, Koedoe, v. 51, n. 1, p. 80-89, 2009.

MAYER, A. M.; POLJAKOFF-MAYBER, A. The germination of seeds. $4^{\text {th }}$ ed. Great Britain: Pergamon Press, 1989. $270 \mathrm{p}$.

MEDEIROS FILHO, S.; FRANÇA, E. A.; INNECCO, R. Germinação de sementes de Operculina macrocarpa (L.) Farwel e Operculina alata (Ham.) Urban. Revista Brasileira de Sementes, Londrina, v. 24, n. 2, p. 102-107, 2002.

MURDOCH, A. J.; ELLIS, R. H. Dormancy, viability and longevity. In: FENNER, M. (Ed.). Seeds: the ecology of regeneration in plant communities. $2^{\text {th }}$ ed. Wallingford: CABI Publishing, 2000. p. 183-214.

NAKAGAWA, J. Testes de vigor basea dos no desempenho das plântulas. In: KRZYZANOWSKI, F. C.; VIEIRA, R. D.; FRANÇA NETO, J. B. (Ed.). Vigor de sementes: conceitos e testes. Londrina: ABRATES, 1999. cap. 2, p. 1-24.
OLIVEIRA, L. M.; DAVIDES, C. A.; CARVALHO, M. L. M. Avaliação de métodos para quebra da dormência e para a desinfestação de sementes de canafístula (Peltophorum dubium (Sprengel) Taubert. Revista Árvore, Viçosa, MG, v. 27, n. 5, p. 597-603, 2003.

PEREIRA, E. W. L.; RIBEIRO, M. C. C.; SOUZA, J. O.; LINHARES, P. C. F.; NUNES, G. H. S. Superação de dormência em sementes de jitirana (Merremia aegyptia L.). Revista Caatinga, Mossoró, v. 20, n. 2, p. 59-62, 2007.

PIÑA-RODRIGUES, F. C. M.; AGUIAR, I. B. Maturação e dispersão de sementes. In: AGUIAR, I. B.; PIÑARODRIGUES, F. C. M.; FIGLIOLIA, M. B. (Org.). Sementes florestais tropicais. Brasília: ABRATES, 1993. p. 83-135.

POPINIGIS, F. Fisiologia da semente. Brasília: AGIPLAN, 1985. 289 p.

RODRIGUES, A. P. D. C.; KOHL, M. C.; PEDRINHO, D. R.; ARIAS, E. R. A.; FAVERO, S. Tratamentos para superar a dormência de sementes de Acacia mangium Willd. Acta Scientiarum Agronomy, Maringá, v. 30, n. 2, p. 279-283, 2008.

SANTOS, L. W.; COELHO, M. F. B.; MAIA, S. S. S.; SILVA, R. C. P.; CÂNDIDO, W. S.; SILVA, A. C. Armazenamento e métodos para a superação da dormência de sementes de mulungu. Semina: Ciências Agrárias, Londrina, v. 34, n. 1, p. 171-178, 2013.

SANZ-ELORZA, M.; DANA-SÁNCHEZ, E. D.; SOBRINO-VESPERINAS, E. Atlas de las plantas alóctonas invasoras en España. Madrid: Dirección General para la Biodiversidad, 2004. 384 p.

SCHMIDT, L. Dormancy and pretreatment. In: OLSEN, K. (Ed.). Guide to handling of tropical and subtropical forest seed. Humlebaek: Danida Forest Seed Centre, 2000. p. 263-303.

SOUZA, V. C.; AGRA, P. F. M.; ANDRADE, L. A.; OLIVEIRA, I. G.; OLIVEIRA, L. S. Germinação de sementes da invasora Sesbania virgata (Cav.) Pers. sob efeito da luz e da temperatura utilizando superação de dormência. Semina: Ciências Agrárias, Londrina, v. 31, n. 4, p. 889-984, 2010.

TRUJILLO, E. Algunos reportes de almacenamiento y tratamientos pregermina- tivos de semillas forestales. En: SIMPOSIO AVANCES EN LA PRODUCCIÓN DE SEMILLAS FORESTALES EN AMÉRICA LATINA, 1995, Turrialba, Costa Rica. Proceedings... Turrialba: Centro Agronomico Tropical de Investigación y Enseñanza, 1995. p. 317-327. 
VAZQUEZ-YANES, C.; OROZCO-SEGOVIA, A. WOODS, W. M. Bruchid seed beetles for control of Patterns of seed longevity and germination in the tropical Parkinsonia aculeata in Australia. In: INTERNATIONAL rainforest. Annual Review of Ecology and Systematics, Stanford, v. 24, n. 1, p. 69-87, 1993. SYMPOSIUM ON BIOLOGICAL CONTROL OF WEEDS, 6., 1985, Vancouver. Proceedings... Vancouver:

VEASEY, E. A.; FREITAS, J. C. T.; SCHAMMASS, E. Agriculture Canada, 1985. p. 855-862.

A. Variabilidade da dormência de sementes entre e dentro de espécies de Sesbania. Scientia Agricola, Piracicaba, v. 57, n. 2, p. 299-304, 2000. 